\title{
Etika Auditor sebagai Pemoderasi Fee Audit, Independensi, dan Kompetensi terhadap Kualitas Audit
}

\author{
Amadea Devota', Hero Priono ${ }^{2}$ \\ *Email:deadevota@gmail.com \\ Universitas Pembangunan Nasional Veteran Jawa Timur
}

\begin{abstract}
The objective of this research is to test and analyze the impact of the audit fee, independency, and competency on audit quality with ethics of auditor as moderation variable of Public Accountant Firm in Surabaya. The sample used in the research as many as 10 Public Accountant Firms which are represented by 46 people of auditors and selected by convenience sampling method. Questionnaires is used as the primary data of this research, distributed right to the auditors in the Public Accountant Firms in Surabaya City that are used as research sample. The data analysis technique used Structural Equation Model (SEM) based Partial Least Square Analysis (PLS). The results in this research showed that (1) audit fee had positive and significant influence on audit quality, (2) independency had negative and significant influence on audit quality, (3) competency had positive and significant influence on quality audit, (4) ethics of auditor could moderate the influence on audit fee of quality audit, (5) ethics of auditor couldn't moderate the influence on independency of quality audit, and (6) ethics of auditor could moderate the influence on competency of quality audit.
\end{abstract}

Keywords: Audit Fee, Audit Quality, Competency, Ethics of Auditor, Independency, Public Accountant.

\section{Pendahuluan}

Laporan keuangan merupakan suatu hal penting yang dibutuhkan di dalam dunia bisnis karena menggambarkan kinerja suatu perusahaan dalam setiap periode yang nantinya akan dibutuhkan oleh dua pihak, yaitu pihak internal dan eksternal. Pihak internal membutuhkan sebagai bahan pertimbangan dalam pengambilan keputusan (decision making). Sedangkan, pihak eksternal membutuhkan sebagai bahan pertimbangan dalam investasi. Oleh karena itu, tiap perusahaan ingin laporan keuangannya dipandang baik bagi pengguna. Akuntan publik menyediakan jasa untuk mengaudit laporan keuangan dengan tujuan untuk meningkatkan kepercayaan berbagai pihak jika laporan keuangan adalah sumber yang reliable dan relevan.

Profesi auditor merupakan profesi yang dapat bertahan jika mendapat kepercayaan dari masyarakat. Namun, belakangan ini banyaknya kasus pelanggaran kode etik yang dilakukan auditor, contohnya, kelalaian yang dilakukan Akuntan Publik (AP) Kasner Sirumapea dari Kantor Akuntan Publik (KAP) Tanubrata, Sutanto, Fahmi, Bambang, dan Rekan di saat mengaudit laporan keuangan PT Garuda Indonesia (Persero) Tbk tahun 2018. Kemenkeu menyatakan bahwa AP dinilai belum tepat dalam menilai substansi transaksi, yakni mengakui pendapatan piutang senilai US\$239,94 juta yang kenyataannya masih tidak diterima oleh perusahaan. Hal ini melibatkan pelanggaran terhadap Standar Audit (SA) 315, 500, serta 560. Sehingga, Kemenkeu memberikan sanksi kepada auditor berupa pembekuan izin selama setahun. OJK atau yang biasa disebut sebagai Otoritas Jasa Keuangan menetapkan sanksi sebanyak Rp 100 juta pada Garuda Indonesia, dan Rp 100 juta pada jajaran Direksi dan Komisaris Garuda Indonesia. Selain itu, Bursa Efek Indonesia (BEI) menerapkan hukuman denda sebesar Rp 250 juta rupiah kepada Garuda Indonesia (Uly, 2019).

Salah satu contoh tersebut menimbulkan keraguan masyarakat atas kualitas audit yang dihasilkan oleh auditor. Kualitas audit adalah kemungkinan auditor untuk menjumpai dan auditor dapat melaporkan kesalahan yang terjadi di laporan keuangan klien. Kualitas auditor dapat mempengaruhi kesimpulan akhir yang dihasilkan dalam laporan hasil audit yang secara 
tidak langsung dapat mempengaruhi keputusan para pengguna, contohnya investor (Hanjani \& Rahardja, 2014). Maka dari itu, auditor diharuskan untuk mempunyai kualitas audit yang baik agar bisa menyelaraskan kepentingan pihak manajemen dengan pemilik. Terdapat sebagian faktor-faktor yang mempengaruhi kualitas audit, contohnya fee audit, independensi, kompetensi, dan etika auditor.

\section{Tinjauan Literatur}

Dalam melakukan pengauditan, auditor diwajibkan memegang teguh prinsip etika auditor agar dapat menyelesaikan tugas dengan tetap berpengang teguh terhadap peraturan yang berlaku. Etika profesi merupakan ciri-ciri yang membedakan tiap-tiap profesi, serta mengatur tindakan anggotanya (Trihapsari \& Anisykurlillah, 2016).

\subsection{Kualitas Audit}

Audit adalah proses sistematik yang digunakan untuk melakukan evaluasi terhadap bahan bukti target dalam tingkat kesesuaian antara laporan keuangan akan standar yang telah ditentukan. Target audit berdasarkan (Wardhatul, In, \& Asyik, 2019) adalah menilai kewajaran suatu laporan keuangan berdasarkan kriteria audit yang sudah ditentukan oleh Ikatan Akuntan Publik Indonesia (IAPI) yang meliputi kriteria umum, standar pekerjaan lapangan dan standar pelaporan. Dapat disimpulkan bahwa hasil dari audit bisa dipandang sesuatu yang mempunyai kualitas dan sesuai dengan standar dari IAPI.

\subsection{Fee audit}

Fee audit adalah upah auditor yang akan diperoleh setelah dia menjalankan tugasnya dalam pengauditan, besaran ini diukur dari tingkat skill yang dibutuhkan, resiko akan tugas yang diambil, seberapa kompleksnya data, serta struktur biaya KAP yang bersangkutan (Andriani \& Nursiam, 2018). Penentuan besaran fee merupakan hal yang penting karena seorang auditor bekerja demi mendapatkan penghasilan. Selain itu, penentuan fee ini bertujuan untuk menghindari perang harga antar Kantor Akuntan Publik yang dapat menyangkut kredibilitas auditor.

Dalam penelitian terdahulu mengenai pengaruh besaran fee audit akan kualitas audit yang sudah diuji oleh (Kusumawardani, 2017) yang menyatakan jika fee audit mempunyai pengaruh positif akan kualitas audit. Hal ini menggambarkan bahwa fee audit merupakan kebutuhan wajib Kantor Akuntan Publik sebagai sarana dalam proses pengauditan karena auditor tentu bekerja untuk memperoleh pendapatan. Sepemikiran dengan kajian yang diuji oleh (Prabhawanti \& Widhiyani, 2018) yang menyatakan jika variabel fee audit mempunyai pengaruh yang positif akan kualitas audit. Dapat ditarik kesimpulan bahwa perusahaan memberi fee audit yang besar biasanya kepada KAP yang telah mendapatkan reputasi tinggi sehingga namanya dikenal dan juga mempunyai kualitas yang tentunya baik juga.

$\mathrm{H}_{1}$ : Besaran fee audit berpengaruh positif terhadap kualitas audit.

\subsection{Independensi}

Independensi merupakan perilaku yang tidak bias dan tidak terpengaruh akan tekanan manapun demi kepentingan bersama. Independensi merupakan faktor yang paling diutamakan untuk menciptakan kualitas audit yang bisa digolongkan baik, dimana auditor yang mempunyai independensi tinggi maka dia akan mengungkapkan apa saja yang telah dia temukan pada proses audit tanpa pengaruh oleh pihak maupun kepentingan manapun. Dalam pernyataan standar umum nomor dua (SA seksi 220 dalam SPAP, 2001) jika "Dalam semua hal yang berhubungan dengan perikatan, independensi dalam sikap mental harus

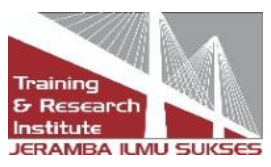


dipertahankan oleh auditor". Profesi auditor tidak berarti di mata masyarakat jika tidak mempunyai sikap independensi.

Ada sebagian penelitian yang menguji tentang sikap independensi terhadap kualitas audit, contohnya penelitian oleh (Wiratama \& Budiartha, 2015) yang menunjukkan jika adanya pengaruh positif antara independensi akan kualitas audit. Kesimpulan yang didapat adalah auditor haruslah menjaga perilaku independensi agar hasil audit menyatakan fakta yang sebenarnya. Dengan demikian, tingginya sikap independensi auditor maka semakin tinggi juga kualitas audit yang diciptakan oleh auditor independen.

$\mathrm{H}_{2}$ : Independensi berpengaruh positif terhadap kualitas audit.

\subsection{Kompetensi}

Sesuai dengan pernyataan standar umum pertama (SA seksi 210 dalam SPAP, 2011) menjabarkan jika audit diharuskan kepada suatu individu atau individu yang mempunyai kemampuan dan seorang auditor yang mempunyai pelatihan teknis. Seorang auditor diharuskan untuk memiliki pengetahuan di bidang auditing dan akuntansi. Menurut (Lesmana \& Machdar, 2015) kompetensi ialah sikap perilaku auditor dalam menjalankan tugasnya, mencakup hasil penelitian yang dilakukan oleh (Bagus \& Astika, 2018) serta (Wardhatul et al., 2019) mengemukakan bahwa kompetensi berpengaruh positif terhadap kualitas audit. Kondisi ini menggambarkan bahwa auditor yang memiliki tingkat kompetensi yang tinggi akan mempermudah auditor dalam menyelesaikan pekerjaannya, dan begitupun sebaliknya.

$\mathrm{H}_{3}$ : Kompetensi berpengaruh positif terhadap kualitas audit.

\subsection{Etika Auditor}

Etika auditor memoderasi hubungan fee audit pada kualitas audit. Dengan penerapan etika auditor secara benar, maka diharapkan auditor dapat memberikan pendapat sesuai dengan fakta/keadaan yang ada. (Prabhawanti \& Widhiyani, 2018) menyatakan bahwa fee audit yang tinggi dapat memenuhi biaya-biaya operasional yang dikeluarkan oleh KAP, sehingga dapat mengasilkan kualitas audit yang baik. Dapat disimpulkan bahwa fee audit yang tinggi akan mempengaruhi peningkatan pendeteksian penyimpangan dalam laporan keuangan sehingga dapat menghasilkan kualitas audit yang baik.

$\mathrm{H}_{4}$ : Etika auditor mampu memoderasi hubungan fee audit terhadap kualitas audit.

Tekanan klien yang dihadapi auditor dapat menyebabkan terganggunya independensi yang dimiliki auditor. Munculnya sikap dilematis terjadi jika di satu sisi auditor ingin mewujudkan keinginan klien namun di satu sisi tindakan tersebut dapat melanggar standar profesi yang telah ditetapkan. Auditor dapat mempertahankan sikap independensi tergantung dari lingkungan ekonomi, lingkungan tertentu, dan etika auditor.

H5: Etika auditor mampu memoderasi hubungan independensi terhadap kualitas audit.

Auditor harus mempunyai pengetahuan yang baik dalam melakukan pengauditan. Apabila auditor dapat mengimbangi pengetahuan yang dimiliki dengan pengalaman yang memadai, maka kualitas audit yang dihasilkan akan baik. (Wardhatul et al., 2019) membuktikan bahwa kompetensi berpengaruh positif terhadap kualitas audit. Hal ini menggambarkan bahwa auditor harus berkompeten dalam melaksanakan tugasnya agar dapat dengan mudah menyelesaikan pekerjaannya sehingga dapat menghasilkan kualitas audit yang baik dan memadai.

Kompetensi yang dimiliki auditor berkaitan dengan etika, Auditor harus memegang teguh

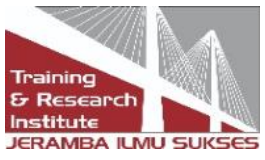


standar etika profesi terhadap organisasi dan profesi mereka, masyarakat, dan diri mereka sendiri. Maka dapat disimpulkan bahwa auditor memiliki tingkat kompetensi yang baik serta didukung dengan pemahaman etika yang baik maka akan sangat berpengaruh terhadap kualitas audit.

H6: Etika auditor mampu memoderasi hubungan kompetensi terhadap kualitas audit.

\section{Metode Penelitian}

Pendekatan kuantitatif adalah metode pendekatan yang akan digunakan di dalam penelitian ini. SmartPLS versi 2.0 for windows adalah software yang digunakan untuk membantu menganalisis data di dalam kajian ini. Penelitian kali ini mempunyai target yaitu untuk menganalisis dan melakukan pengujian apakah besaran fee audit, independensi, dan kompetensi sebagai variabel independen, berpengaruh terhadap kualitas audit sebagai variabel dependen, dengan etika auditor sebagai variabel moderasi. Penelitian ini dilakukan di Kantor Akuntan Publik di Kota Surabaya yang telah tercantum namanya pada Direktori Ikatan Akuntan Publik Indonesia (IAPI) 2017.

Data primer merupakan satuan data yang dipergunakan sebagai data di dalam penelitian ini, metode survey digunakan dalam pengumpulan data yang didapat melalui penyebaran kuisioner yang langsung diberikan pada auditor yang berada di Kantor Akuntan Publik di Surabaya. Jawaban pertanyaan responden dihitung dengan skala likert empat poin.

Jumlah populasi yang digunakan dalam penelitian ini adalah sejumlah 74 auditor yang bekerja di Kantor Akuntan Publik di Kota Surabaya. Teknik penentuan sampelnya adalah convenience sampling, yaitu pengumpulan sample tanpa adanya paksaan sehingga mereka dengan senang hati untuk memberi jawaban. Setelah melakukan convenience sampling, terkumpul jumlah sampel menjadi 46 auditor.

Penyebaran kuesioner dilakukan sejumlah 74 kuesioner, namun tidak sepenuhnya kuesioner tersebut kembali dikarenakan banyak Kantor Akuntan Publik yang enggan memberikan informasi karena auditor sedang sibuk melakukan penugasan. Hasil penyebaran dan pengembalian kuesioner dapat dilihat di Tabel 1.

Tabel 1. Daftar Penyebaran dan Pengembalian Kuesioner

\begin{tabular}{llcc}
\hline No & \multicolumn{1}{c}{ Nama Kantor Akuntan Publik } & $\begin{array}{c}\text { Kuesioner } \\
\text { Disebar }\end{array}$ & $\begin{array}{c}\text { Kuesioner } \\
\text { Kembali }\end{array}$ \\
\hline 1 & KAP HABIB BASUNI \& HERYADI & 5 & 5 \\
2 & KAP CHATIM, ATJENG, SUGENG \& REKAN & 5 & 5 \\
3 & KAP Drs. ROBBY BUMULO & 5 & 5
\end{tabular}


4 KAP RICHARD RISAMBESSY \& REKAN (PUSAT)

5 KAP SUPOYO, SUTJAHJO, SUBYANTARA \& REKAN

KAP Drs. BASRI HARDJOSUMARTO, M.Si, Ak. \& REKAN (PUSAT)

KAP TERAMIHARDJA, PRADHONO \& CHANDRA (CAB)

8 KAP HADORI SUGIARTO ADI \& REKAN (CAB)

9 KAP DRS. HANANTA BUDIANTO \& REKAN (CAB)

10 KAP Drs. ARIEF H. P.

11 KAP BUNTARAN \& LISAWATI

12 KAP MADE SUDARMA, THOMAS \& DEWI (CAB)

13 Kreston HHES International Public Accounting Firm

14 KAP DRS. BAMBANG SISWANTO

15 KAP BENNY, TONY, FRANS \& DANIEL (CAB)

16 KAP Drs. CHANDRA DWIYANTO

Total Kuesioner yang Disebar

Total Kuesioner yang Kembali

Sumber: Data diolah, 2021

\section{Hasil dan Pembahasan}

Kajian ini mengaplikasikan model Structural Equation Model (SEM) dan juga model analisis Partial Least Square (PLS) dalam melakukan uji hipotesis yang telah diajukan pada uji terdahulu. Analisis PLS melakukan pengujian yang dibantu dengan software SmartPLS versi 2.0 for windows.

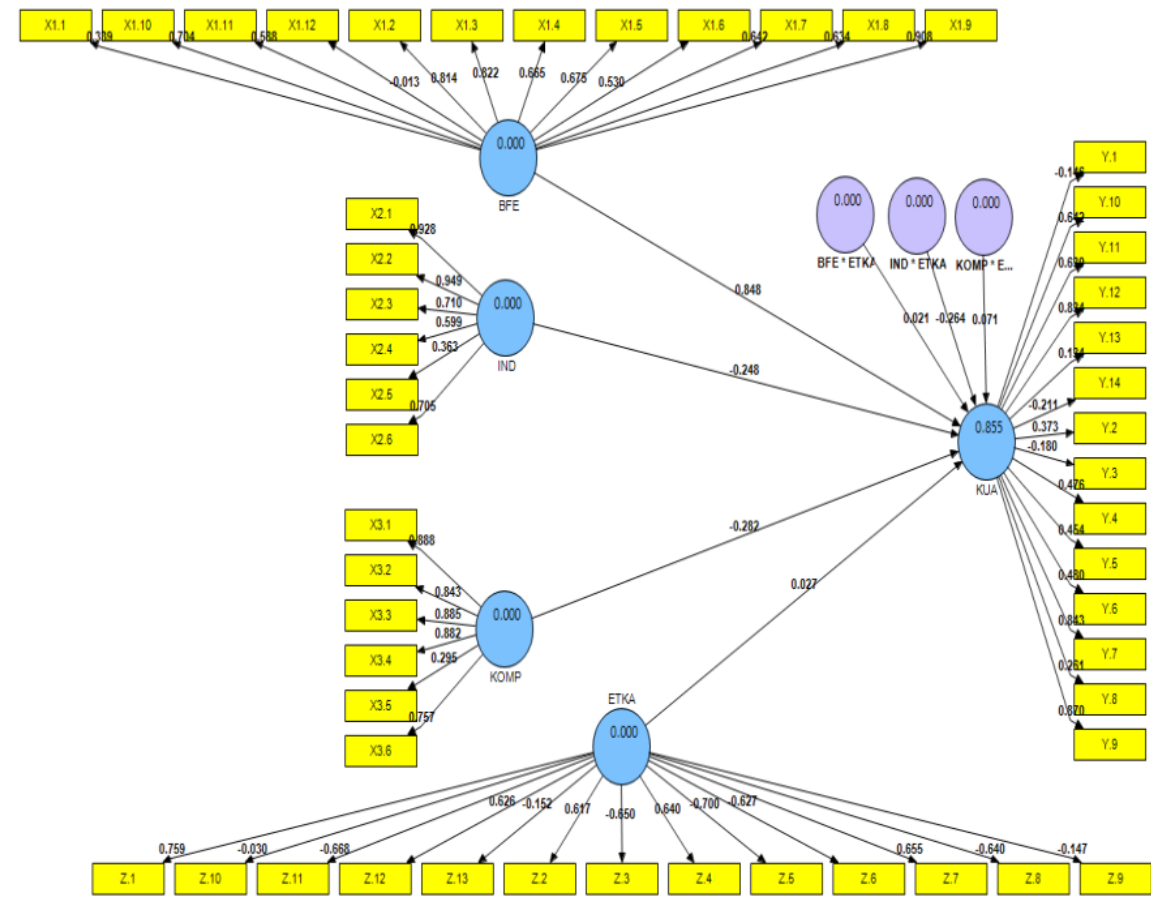

Gambar 1. Hasil Perhitungan Nilai Outer Loading Model Awal 


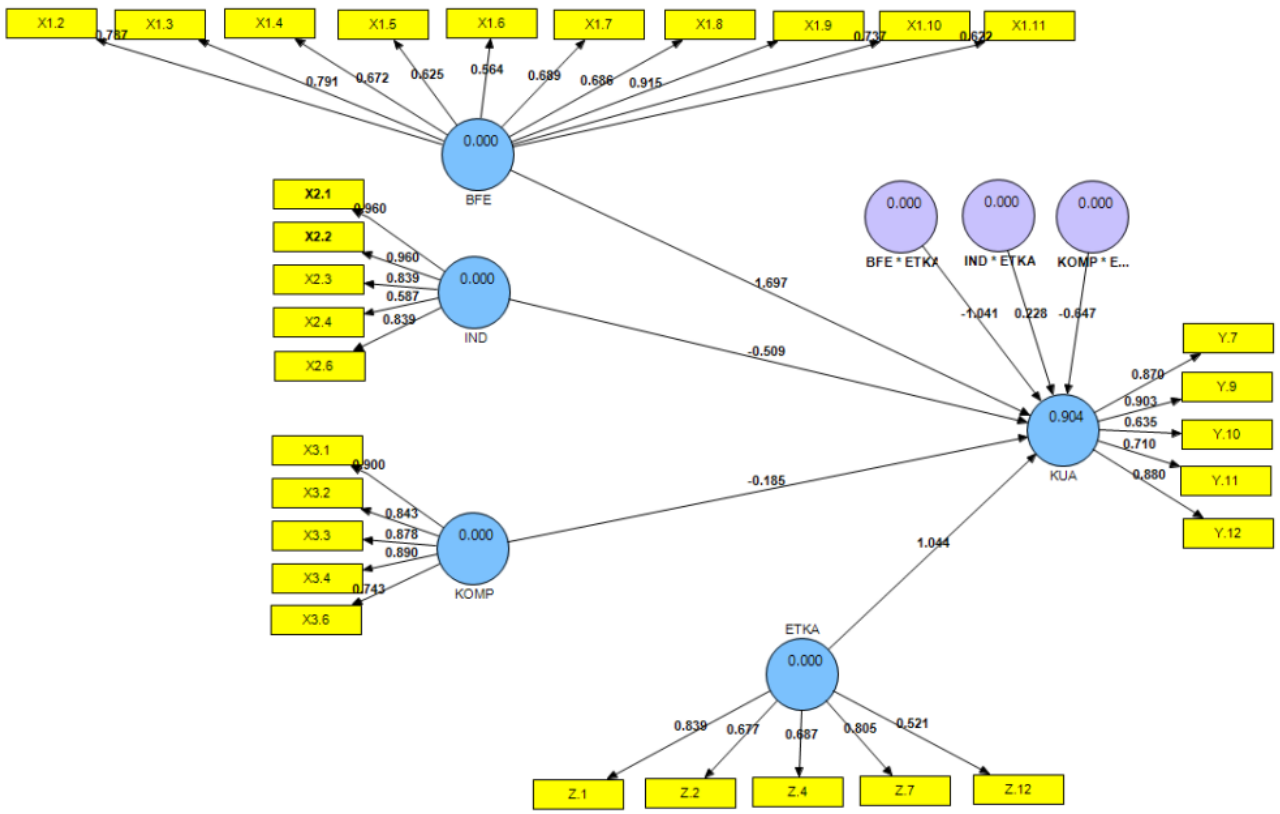

Gambar 2: Hasil Perhitungan Nilai Outher Loading Model Modifikasi

Sumber: Data olahan PLS 2.0, 2021

"Convergent validity" dilihat dari outer loadings. Batas loading factor sebanyak 0,5. Jika nilai loading factor $>0,5$ maka convergent validity terpenuhi, jika nilai loading factor $<0,5$ maka konstruk harus di drop dari analisis (Ghozali, 2008). Dibawah ini adalah output convergent validity yang menggunakan aplikasi software SmartPLS versi 2.0.

Berdasarkan Gambar 2, bisa disimpulkan jika proksi mempunyai nilai outer loading factor yang bernilai lebih besar dari 0.5. Karena itu nilai outer loading factor dianggap pantas dijadikan sebagai indikator yang bisa merefleksikan masing-masing variabel yang bersesuaian.

Discriminant validity diukur bersumber dari cross loading outer dan membandingkan antara AVE dengan kuadrat korelasi antar variabel. Discriminat validty dapat dikatakan baik jika dapat menjabarkan variabel indikatornya lebih tinggi daripada variabel lain. Tabel 2 merupakan nilai discriminant validity untuk masing-masing indicator variabel.

Tabel 2. Hasil Perhitungan Discriminant validity

\begin{tabular}{cccccc} 
Indikator & $\begin{array}{c}\text { BFE } \\
(\mathbf{X 1})\end{array}$ & $\begin{array}{c}\text { IND } \\
(\mathbf{X})\end{array}$ & $\begin{array}{c}\text { KOMP } \\
(\mathbf{X 3})\end{array}$ & KUA $(\mathbf{Y})$ & $\begin{array}{c}\text { ETKA } \\
(\mathbf{Z})\end{array}$ \\
\hline $\mathbf{X 1 . 4}$ & 0.816645 & 0.129461 & 0.094646 & 0.479457 & 0.237268 \\
\hline $\mathbf{X 1 . 5}$ & 0.516200 & 0.255646 & 0.232428 & 0.462437 & 0.473275 \\
\hline $\mathbf{X 1 . 6}$ & 0.703464 & 0.164362 & 0.252272 & 0.272074 & 0.195109 \\
\hline $\mathbf{X 1 . 7}$ & 0.833295 & 0.331714 & 0.107762 & 0.444625 & 0.139612
\end{tabular}




\begin{tabular}{|c|c|c|c|c|c|}
\hline Indikator & $\begin{array}{l}\text { BFE } \\
(\mathbf{X} 1)\end{array}$ & $\begin{array}{l}\text { IND } \\
\text { (X2) }\end{array}$ & $\begin{array}{c}\text { KOMP } \\
\text { (X3) }\end{array}$ & KUA (Y) & $\begin{array}{c}\text { ETKA } \\
(\mathrm{Z})\end{array}$ \\
\hline X1.8 & 0.814071 & 0.396965 & 0.166583 & 0.417493 & 0.147140 \\
\hline X1.10 & 0.913391 & 0.395110 & 0.081047 & 0.410825 & 0.223877 \\
\hline X1.11 & 0.763189 & 0.511166 & 0.042950 & 0.264566 & 0.311191 \\
\hline X2.3 & 0.481195 & 0.801640 & -0.240737 & -0.039067 & 0.221361 \\
\hline X2.4 & 0.214436 & 0.893124 & -0.034559 & -0.060295 & 0.097774 \\
\hline $\mathrm{X} 2.6$ & 0.535029 & 0.814746 & -0.216421 & -0.009524 & 0.222188 \\
\hline X3.1 & 0.200574 & $\begin{array}{c}- \\
0.161083\end{array}$ & 0.899472 & 0.586888 & 0.402468 \\
\hline X3.2 & 0.103693 & 0.084834 & 0.842770 & 0.455165 & 0.471138 \\
\hline X3.3 & 0.309035 & 0.036627 & 0.879021 & 0.552910 & 0.534924 \\
\hline X3.4 & 0.077586 & 0.341939 & 0.889496 & 0.713115 & 0.367827 \\
\hline X3.6 & 0.094880 & 0.005065 & 0.744272 & 0.532489 & 0.369426 \\
\hline Y.7 & 0.597430 & $\begin{array}{c}- \\
0.009988\end{array}$ & 0.550084 & 0.866863 & 0.373973 \\
\hline Y.9 & 0.402329 & 0.224366 & 0.533554 & 0.899098 & 0.349514 \\
\hline Y.10 & 0.208033 & 0.215546 & 0.518307 & 0.641425 & 0.359695 \\
\hline Y.11 & 0.384370 & 0.088820 & 0.474014 & 0.710958 & 0.284624 \\
\hline Y.12 & 0.501911 & 0.107260 & 0.655452 & 0.881460 & 0.386304 \\
\hline Z.2 & 0.236507 & 0.029220 & 0.362655 & 0.334661 & 0.785839 \\
\hline Z.4 & 0.241121 & 0.208382 & 0.469461 & 0.376871 & 0.815901 \\
\hline Z.12 & 0.295541 & 0.181566 & 0.333659 & 0.317695 & 0.767727 \\
\hline
\end{tabular}

Sumber: Data olahan PLS 2.0, 2020

Tabel 3. Hasil Perhitungan Discriminant validity Terhadap Variabel Moderating 


\begin{tabular}{|c|c|c|c|}
\hline Indikator & $\begin{array}{c}\text { BFE } * \\
\text { ETKA } \\
(\mathbf{X 1} * \mathbf{Z})\end{array}$ & $\begin{array}{l}\text { IND } * \\
\text { ETKA } \\
(\mathbf{X} 2 * Z)\end{array}$ & $\begin{array}{c}\text { KOMP } \\
* \text { ETKA } \\
\left(\mathrm{X}^{*} \mathrm{Z}\right)\end{array}$ \\
\hline $\mathrm{X} 1.4 * \mathrm{Z} .12$ & 0.807433 & 0.553395 & 0.592822 \\
\hline $\mathrm{X} 1.4 * \mathrm{Z} .2$ & 0.805514 & 0.343177 & 0.543399 \\
\hline X1.4*Z.4 & 0.838535 & 0.489968 & 0.611314 \\
\hline $\mathrm{X} 1.5 * \mathrm{Z} .12$ & 0.687520 & 0.556488 & 0.567862 \\
\hline $\mathrm{X} 1.5 * \mathrm{Z} .2$ & 0.709587 & 0.453313 & 0.579462 \\
\hline $\mathrm{X} 1.5 * \mathrm{Z} .4$ & 0.731859 & 0.546633 & 0.634642 \\
\hline $\mathrm{X} 1.6 * \mathrm{Z} .12$ & 0.784610 & 0.572772 & 0.641619 \\
\hline X1.6*Z.2 & 0.774899 & 0.322948 & 0.605833 \\
\hline X1.6*Z.4 & 0.839898 & 0.508303 & 0.702622 \\
\hline $\mathrm{X} 1.7 * \mathrm{Z} .12$ & 0.867433 & 0.624799 & 0.548362 \\
\hline $\mathrm{X} 1.7 * \mathrm{Z} .2$ & 0.807455 & 0.396256 & 0.449880 \\
\hline $\mathrm{X} 1.7 * \mathrm{Z} .4$ & 0.825917 & 0.527905 & 0.510500 \\
\hline $\mathrm{X} 1.8 * \mathrm{Z} .12$ & 0.820927 & 0.648031 & 0.580055 \\
\hline $\mathrm{X} 1.8 * \mathrm{Z} .2$ & 0.802173 & 0.451427 & 0.524122 \\
\hline $\mathrm{X} 1.8 * \mathrm{Z} .4$ & 0.836847 & 0.590069 & 0.585105 \\
\hline $\mathrm{X} 1.10 * \mathrm{Z} .12$ & 0.839733 & 0.666856 & 0.594200 \\
\hline $\mathrm{X} 1.10 * \mathrm{Z} .2$ & 0.901209 & 0.494164 & 0.582813 \\
\hline $\mathrm{X} 1.10 * \mathrm{Z} .4$ & 0.853001 & 0.615769 & 0.602061 \\
\hline X1.11*Z.12 & 0.862141 & 0.689360 & 0.457267 \\
\hline X1.11*Z.2 & 0.800514 & 0.515604 & 0.380073 \\
\hline $\mathrm{X} 1.11 * \mathrm{Z} .4$ & 0.783580 & 0.603891 & 0.402953 \\
\hline $\mathrm{X} 2.3 * \mathrm{Z} .12$ & 0.633435 & 0.833911 & 0.171366 \\
\hline $\mathrm{X} 2.3 * \mathrm{Z} .2$ & 0.510067 & 0.682739 & 0.093221 \\
\hline
\end{tabular}




\begin{tabular}{|c|c|c|c|}
\hline Indikator & $\begin{array}{c}\text { BFE * } \\
\text { ETKA } \\
(\mathbf{X 1} * \mathbf{Z})\end{array}$ & $\begin{array}{l}\text { IND * } \\
\text { ETKA } \\
(\mathbf{X} 2 * \mathbf{Z})\end{array}$ & $\begin{array}{c}\text { KOMP } \\
* \text { ETKA } \\
(\mathrm{X} 3 * \mathrm{Z})\end{array}$ \\
\hline $\mathrm{X} 2.3 * \mathrm{Z} .4$ & 0.541717 & 0.750178 & 0.131000 \\
\hline $\mathrm{X} 2.4 * \mathrm{Z} .12$ & 0.590487 & 0.880885 & 0.510007 \\
\hline $\mathrm{X} 2.4 * \mathrm{Z} .2$ & 0.484124 & 0.853768 & 0.407381 \\
\hline $\mathrm{X} 2.4 * \mathrm{Z} .4$ & 0.513126 & 0.881874 & 0.458496 \\
\hline $\mathrm{X} 2.6 * \mathrm{Z} .12$ & 0.611241 & 0.846933 & 0.176198 \\
\hline $\mathrm{X} 2.6 * \mathrm{Z} .2$ & 0.575909 & 0.810161 & 0.121880 \\
\hline $\mathrm{X} 2.6 * \mathrm{Z} .4$ & 0.562925 & 0.819746 & 0.146700 \\
\hline X3.1*Z.12 & 0.662622 & 0.475507 & 0.848524 \\
\hline X3.1*Z.2 & 0.607653 & 0.211690 & 0.890497 \\
\hline X3.1*Z.4 & 0.599900 & 0.349206 & 0.875753 \\
\hline $\mathrm{X} 3.2 * \mathrm{Z} .12$ & 0.633829 & 0.484061 & 0.853213 \\
\hline $\mathrm{X} 3.2 * \mathrm{Z} .2$ & 0.543768 & 0.233675 & 0.836575 \\
\hline $\mathrm{X} 3.2 * \mathrm{Z} .4$ & 0.575043 & 0.372253 & 0.873583 \\
\hline X3.3*Z.12 & 0.672508 & 0.547499 & 0.839552 \\
\hline $\mathrm{X} 3.3 * \mathrm{Z} .2$ & 0.667971 & 0.362359 & 0.917530 \\
\hline $\mathrm{X} 3.3 * \mathrm{Z} .4$ & 0.653425 & 0.474701 & 0.889748 \\
\hline $\mathrm{X} 3.4 * \mathrm{Z} .12$ & 0.644625 & 0.397145 & 0.889354 \\
\hline X3.4*Z.2 & 0.530363 & 0.104195 & 0.846467 \\
\hline $\mathrm{X} 3.4 * \mathrm{Z} .4$ & 0.544826 & 0.242508 & 0.871658 \\
\hline X3.6*Z.12 & 0.581328 & 0.514747 & 0.801659 \\
\hline X3.6*Z.2 & 0.527937 & 0.312500 & 0.831486 \\
\hline X3.6*Z.4 & 0.544588 & 0.428532 & 0.843908 \\
\hline
\end{tabular}

Sumber: Data olahan PLS 2.0, 2021

Berdasarkan Tabel tersebut jumlah cross loading bagi seluruh indikator pada tiap-tiap 
variabel laten dalam variabel moderating telah memiliki nilai cross loading yang lebih besar apabila dibandingkan terhadap nilai dari variabel laten yang lain. Sehingga artinya seluruh variabel laten dalam variabel moderating telah memiliki nilai discriminant validity yang sesuai, dan juga beberapa variabel laten dalam variabel moderating sudah mempunyai penghitungan dengan korelasi yang tinggi terhadap nilai konstruk yang lain.

Tabel 4. Hasil Perhitungan Average Variance Extracted (AVE)

\begin{tabular}{cc} 
Variabel & AVE \\
\hline BFE $(\mathbf{X} 1)$ & 0.600295 \\
\hline IND (X2) & 0.701370 \\
\hline KOMP $(\mathbf{X 3 )}$ & 0.727427 \\
\hline KUA $(\mathbf{Y})$ & 0.650738 \\
\hline ETKA $(\mathbf{Z})$ & 0.624213 \\
\hline BFE * ETKA $(\mathbf{X} 1 * \mathbf{Z})$ & 0.656409 \\
\hline IND * ETKA $(\mathbf{X} 2 * \mathbf{Z})$ & 0.672503 \\
\hline KOMP * ETKA & 0.741514 \\
\hline
\end{tabular}

Sumber: Data olahan PLS 2.0, 2021

Berdasarkan hasil di atas, semua variabel mempunyai "nilai discriminant validity di atas 0,50 ". Temuan dari nilai tersebut, bisa kita simpulkan yaitu semua variabel sudah valid serta bisa memberi jaminan terhadap pengukuran. Sesudah variabel dapat dikatakan valid, artinya dapat dilaksanakan uji realibilitas kepada semua variabel yang diterapkan pada pembahasan studi ini.

Pengujian reliabilitas dibutuhkan dalam menilai stabilitas serta konsistensi dari sebuah instrumen untuk menghitung sebuah konsep maupun variabel. Penilaian reliabilitas juga bisa diukur berdasarkan ukuran reliabilitas dari konstruk (Ghozali, 2008). Dalam pembahasan studi ini, reliabilitas bisa dinilai berdasarkan penghitungan "nilai composite reliability". Dalam penentuan reliabel maupun tidak reliabelnya suatu alat ukur dapat dinilai berdasarkan "koefisien reliabilitas". "Koefisien reliabilitas harus lebih besar dari 0,70" (Ghozali, 2008).

Tabel 5. Hasil pengukuran Composite Reliability

\begin{tabular}{cc} 
Variabel & Composite Reliability \\
\hline BFE (X1) & 0.911262 \\
\hline IND (X2) & 0.875459 \\
\hline KOMP (X3) & 0.929995
\end{tabular}




\begin{tabular}{cc} 
KUA $(\mathbf{Y})$ & 0.901587 \\
\hline $\mathbf{E T K A}(\mathbf{Z})$ & 0.832779 \\
\hline $\mathbf{B F E} * \mathbf{E T K A}(\mathbf{X} 1 * \mathbf{Z})$ & 0.975588 \\
\hline IND * $\mathbf{E T K A}(\mathbf{X} 2 * \mathbf{Z})$ & 0.948399 \\
\hline KOMP * ETKA $(\mathbf{X 3} * \mathbf{Z})$ & 0.977264 \\
\hline
\end{tabular}

Sumber: Data olahan PLS 2.0, 2021

Berlandaskan pada Tabel tersebut, semua variabel sudah mempunyai "nilai composite reliability lebih besar dari 0,70 ". Berdasarkan temuan tersebut, bisa disimpulkan yaitu semua variabel pada pembahasan studi ini sudah reliabel serta bisa diandalkan dalam penerapan pengujian analisis berikutnya.

Penghitungan pada "inner model" dalam pengujian "pengaruh antar variabel" pada pembahasan studi ini menggunakan nilai $\mathrm{R}^{2}$. " $R$ Square $\left(\mathrm{R}^{2}\right)$ ” yang juga dikatakan sebagai "koefisien determinasi" yang menjadi alat ukur "kesesuaian model (goodness of fit)" terhadap "persamaan regresi", yakni dengan menyajikan "persentase variasi total dalam variabel terikat" yang dinilai berdasarkan "variabel bebas". "Nilai $\mathrm{R}^{2}$ terletak antara $0-1$ ", serta kesesuaian model dapat disebut baik apabila $\mathrm{R}^{2}$ mendekati nilai 1 .

Tabel 6. Hasil pengukuran $R$ Square $\left(\mathrm{R}^{2}\right)$

\begin{tabular}{cc}
\hline Variabel & R Square \\
\hline BFE $(X 1)$ & - \\
\hline IND $(X 2)$ & - \\
\hline KOMP $(\mathbf{X})$ & - \\
\hline KUA $(\mathbf{Y})$ & - \\
\hline ETKA $(\mathbf{Z})$ & - \\
\hline BFE $*$ ETKA $(X 1 * Z)$ & - \\
\hline IND * ETKA $(X 2 * Z)$ & - \\
\hline KOMP * ETKA $(X 3 * Z)$ & - \\
\hline
\end{tabular}

Sumber : Data olahan PLS 2.0, 2021

Berdasarkan table tersebut "nilai $\mathrm{R}^{2}$ sebesar 0.693589 untuk variabel (Y) Kualitas Audit" yang artinya yaitu $\left(\mathrm{X}_{1}\right)$ Besaran Fee Audit, $\left(\mathrm{X}_{2}\right)$ Independensi, $\left(\mathrm{X}_{3}\right)$ Kompetensi, serta $(\mathrm{Z})$ Etika Auditor dapat dijabarkan oleh variabel (Y) Kualitas Audit dengan persentase 69.3\% 
serta besaran lainnya $30.7 \%$ tidak disebutkan pada pembahasan studi ini.

Nilai penghitungan "koefisien jalur antar konstruk" wajib mempunyai ukuran yang mencukupi. Signifikan atau tidak hubungan bisa dilihat berdasarkan "prosedur Bootstrapping atau Jacknifing". Angka yang muncul berupa ukuran t-hitung yang dibandingkan terhadap ttabel. Jika "nilai t-hitung > t-tabel (1.96) pada taraf signifikansi ( $\alpha$ 5\%)" artinya "nilai estimasi koefisien jalur" dikatakan signifikan. Pembahasan studi ini mempunyai tujuh hipotesis penilaian. Temuan dari setiap pengujian tersebut tersaji di bawah:

Tabel 7. Hasil pengukuran Bootstrapping

\begin{tabular}{|c|c|c|c|c|c|c|}
\hline Hubungan Antar Variabel & $\begin{array}{c}\text { Original } \\
\text { Sample (O) }\end{array}$ & $\begin{array}{c}\text { Sample } \\
\text { Mean (M) }\end{array}$ & $\begin{array}{l}\text { Standard } \\
\text { Deviation } \\
\text { (STDEV) }\end{array}$ & $\begin{array}{c}\text { Standard } \\
\text { Error } \\
\text { (STERR) }\end{array}$ & $\begin{array}{c}\text { T Statistics } \\
(\mid \mathbf{O} / \text { STERR } \mid)\end{array}$ & Keterangan \\
\hline $\begin{array}{c}\text { BFE } * \text { ETKA }(\mathbf{X} 1 * Z)->\text { KUA } \\
(\mathbf{Y})\end{array}$ & -1.799946 & -1.661032 & 0.249593 & 0.249593 & 7.211539 & Signifikan \\
\hline $\begin{array}{c}\text { IND } * \text { ETKA }(\mathbf{X} 2 * Z)->\text { KUA } \\
(Y)\end{array}$ & 0.270059 & 0.031772 & 0.229345 & 0.229345 & 1.177525 & Tdk Signifikan \\
\hline $\begin{array}{c}\text { KOMP } * \operatorname{ETKA~}\left(\mathbf{X}^{*} \mathbf{Z}\right)-> \\
\operatorname{KUA}(\mathbf{Y})\end{array}$ & -2.166671 & -2.018480 & 0.462522 & 0.462522 & 4.684477 & Signifikan \\
\hline BFE (X1) -> KUA (Y) & 1.639892 & 1.571294 & 0.162235 & 0.162235 & 10.108136 & Signifikan \\
\hline IND (X2) -> KUA (Y) & -0.423931 & -0.238535 & 0.199765 & 0.199765 & 2.122154 & Signifikan \\
\hline KOMP (X3) -> KUA (Y) & 1.719687 & 1.620820 & 0.241430 & 0.241430 & 7.122917 & Signifikan \\
\hline ETKA (Z) -> KUA (Y) & 2.286837 & 2.231684 & 0.346689 & 0.346689 & 6.596223 & Signifikan \\
\hline
\end{tabular}

Sumber : Data olahan PLS 2.0, 2021

Hipotesis pertama mengenai "pengaruh besaran fee audit terhadap kualitas audit" yang memperlihatkan temuan bahwa "nilai koefisien (standardized coefficient) positif sebesar 1.639892 dan t-Statistik sebesar $10.108136>$ t-tabel (1.96)" artinya $\mathrm{H}_{1}$ dapat dibuktikan, sehingga dapat disimpulkan bahwa "pengaruh besaran fee audit terhadap kualitas audit terbukti berpengaruh positif signifikan". Temuan tersebut memperlihatkan bahwa dengan meningkatnya fee audit yang didapatkan oleh auditor, bisa mendukung kualitas audit yang tinggi. Misalnya, semakin tinggi fee audit dapat mendukung kompleksitas jasa audit yang dapat diberikan auditor, maka dapat menciptakan kualitas audit yang tinggi. Temuan tersebut didukung oleh pembahasan studi yang diterapkan oleh (Kusumawardani, 2017) serta (Prabhawanti \& Widhiyani, 2018).

Hipotesis kedua mengenai "pengaruh independensi terhadap kualitas audit" yang memperlihatkan temuan bahwa "nilai koefisien (standardized coefficient) negatif sebesar 0.423931 dan t-Statistik sebesar $2.122154>$ t-tabel (1.96)" artinya $\mathrm{H}_{2}$ tidak dapat dibuktikan, sehingga dapat disimpulkan bahwa "pengaruh independensi terhadap kualitas audit terbukti berpengaruh negatif signifikan". Pada saat penugasan audit, auditor diharuskan untuk bersikap independen demi meningkatkan kualitas audit. Hal ini dapat berpengaruh terhadap peningkatan kepercayaan publik kepada hasil kualitas audit yang dibuat oleh auditor. Peningkatan kepercayaan oleh masyarakat dapat dilakukan dengan cara, misalnya penerbitan surat bahwa tidak terdapat koneksi dari auditor terhadap klien. Temuan dari pembahasan studi ini didukung oleh (Bagus \& Astika, 2018) serta (Trihapsari \& Anisykurlillah, 2016) yang menjelaskan bahwa "independensi tidak berpengaruh terhadap kualitas audit".

Hipotesis ketiga mengenai "pengaruh kompetensi terhadap kualitas audit" yang memperlihatkan temuan bahwa "nilai koefisien (standardized coefficient) positif sebesar 1.719687 dan t-Statistik sebesar $7.122917>$ t-tabel (1.96)" artinya hipotesis $\mathrm{H}_{3}$ dapat dibuktikan, sehingga dapat disimpulkan bahwa "pengaruh kompetensi terhadap kualitas audit terbukti berpengaruh positif signifikan". Semakin luasnya pengetahuan serta pengalaman 
yang dipunyai oleh auditor, dapat membentuk hasil kualitas audit dengan baik juga, karena dengan dua hal tersebut, pengerjaan audit akan lebih mudah. Temuan dari pembahasan studi ini didukung oleh (Nurjanah \& Kartika, 2016), (Ningtyas \& Aris, 2016), serta (Falatah \& Sukirno, 2018) yang menjelaskan bahwa "kompetensi memiliki pengaruh positif dan signifikan terhadap kualitas audit".

Hipotesis keempat mengenai "pengaruh etika auditor terhadap kualitas audit" yang memperlihatkan temuan bahwa "nilai koefisien (standardized coefficient) positif sebesar 2.286837 dan t-Statistik sebesar $6.596223>$ t-tabel (1.96)", dan juga "pengaruh moderasi hubungan besaran fee audit terhadap kualitas audit yang dimoderasi oleh etika auditor" yang memperlihatkan temuan bahwa "nilai koefisien (standardized coefficient) negatif sebesar 1.799946 dan t-Statistik sebesar $7.211539>$ t-tabel (1.96)" artinya hipotesis $\mathrm{H}_{4}$ dapat dibuktikan, sehingga dapat disimpulkan bahwa "etika auditor terbukti mampu memoderasi hubungan besaran fee audit terhadap kualitas audit". Etika auditor terbukti dapat memperkuat hubungan antara "besaran fee audit dengan kualitas audit". Dengan meningkatnya etika yang dilakukan oleh auditor artinya kualitas audit yang dihasilkan juga turut meningkat karena pada saat fee yang diberikan kepada auditor tinggi maka dapat mendukung kompleksitas jasa yang diberikan auditor dan perluasan prosedur audit. Temuan dari pembahasan studi ini tidak didukung oleh pembahasan studi dari (Prabhawanti \& Widhiyani, 2018) yang menjelaskan bahwa "etika auditor tidak mampu memoderasi hubungan besaran fee auditor dengan kualitas audit".

Hipotesis kelima mengenai "pengaruh etika auditor terhadap kualitas audit" yang memperlihatkan temuan bahwa "nilai koefisien (standardized coefficient) positif sebesar 2.286837 dan t-Statistik sebesar $6.596223>$ t-tabel (1.96)", dan juga "pengaruh moderasi hubungan independensi terhadap kualitas audit yang dimoderasi oleh Etika Auditor" yang memperlihatkan temuan bahwa "nilai koefisien (standardized coefficient) positif sebesar 0.270059 dan t-Statistik sebesar $1.177525<\mathrm{t}$-tabel (1.96)" artinya hipotesis $\mathrm{H}_{5}$ tidak dapat dibuktikan, sehingga dapat disimpulkan bahwa "etika auditor terbukti tidak mampu memoderasi hubungan independensi terhadap kualitas audit". Etika auditor tidak dapat mempengaruhi independensi, namun mempengaruhi kepercayaan masyarakat pada kualitas jasa audit. Temuan dari pembahasan studi ini didukung oleh pembahasan studi dari (Bagus \& Astika, 2018) serta (Wardhatul et al., 2019) yang menjelaskan bahwa "etika auditor tidak mampu memoderasi hubungan independensi dengan kualitas audit”.

Hipotesis keenam mengenai "pengaruh etika auditor terhadap kualitas audit" yang memperlihatkan temuan bahwa "nilai koefisien (standardized coefficient) positif sebesar 2.286837 dan t-Statistik sebesar $6.596223>$ t-tabel (1.96)", dan juga "pengaruh moderasi hubungan kompetensi terhadap kualitas audit yang dimoderasi oleh etika auditor" yang memperlihatkan temuan bahwa "nilai koefisien (standardized coefficient) negatif sebesar 2.166671 dan t-Statistik sebesar $4.684477>$ t-tabel (1.96)" artinya hipotesis $\mathrm{H}_{6}$ dapat dibuktikan, sehingga dapat disimpulkan bahwa "etika auditor terbukti mampu memoderasi hubungan kompetensi terhadap kualitas audit". Kualitas audit yang baik dapat ditunjang dengan kompetensi serta etika auditor. Jika pelaku auditor tidak mempunyai tingkat pemahaman serta pengalaman yang terlalu tinggi, namun di saat penugasan audit disertai dengan penerapan etika auditor yang benar, maka auditor tersebut tetap dapat membentuk hasil kualitas audit berkualitas tinggi, apabila dibandingkan terhadap auditor yang mempunyai tingkat kompetensi yang tinggi namun tidak memegang teguh etika auditor saat pengauditan (Mariyanto \& Praptoyo, 2017). Temuan dari pembahasan studi ini didukung oleh pembahasan studi dari (Darayasa \& Wisadha, 2016) yang menjelaskan bahwa "etika auditor 
mampu memoderasi hubungan kompetensi dengan kualitas audit”.

Berlandaskan temuan dari analisis mengenai etika auditor sebagai pemoderasi fee audit, independensi, dan kompetensi pada kualitas audit, kesimpulan yang didapat yakni "fee audit berpengaruh positif signifikan terhadap kualitas audit". Artinya bahwa dengan meningkatnya fee audit yang diberikan kepada auditor artinya kualitas audit yang dibentuk juga menjadi semakin baik. "Independensi berpengaruh negatif signifikan terhadap kualitas audit". Artinya bahwa terdapat kewajiban dalam peningkatan sikap independensi dari para pelaku auditor agar dapat menghasilkan kualitas audit yang semakin baik juga. "Kompetensi berpengaruh positif signifikan terhadap kualitas audit". Artinya bahwa tingkat kompetensi yang tinggi akan berguna bagi auditor dalam menyelesaikan masalah dalam pengauditan, karena luasnya pengetahuan dan pengalaman yang dimiliki auditor. "Etika auditor mampu memoderasi hubungan fee audit terhadap kualitas audit". Kesimpulannya yaitu dengan meningkatnya etika yang diterapkan oleh auditor juga dapat berdampak pada peningkatan dari kualitas audit yang dibentuk karena ketika fee yang ditawarkan terhadap auditor semakin tinggi sehingga dapat mendukung kompleksitas jasa yang diberikan auditor dan perluasan prosedur audit. "Etika auditor tidak mampu memoderasi hubungan independensi terhadap kualitas audit". Kesimpulannya yaitu auditor sudah tidak lagi menerapkan etika auditor di setiap penugasan ataupun saat melawan konflik kepentingan tertentu. "Etika auditor terbukti mampu memoderasi hubungan kompetensi terhadap kualitas audit". Kesimpulannya yaitu kualitas audit yang dihasilkan oleh auditor dipengaruhi oleh interaksi etika auditor dan kompetensi yang dimiliki auditor.

Berlandaskan dari temuan serta kesimpulan dari pembahasan studi tersebut, sehingga saran yang bisa dibentuk yaitu untuk meningkatkan etika auditor supaya bisa menciptakan kinerja yang lebih optimal. Dalam hal pengembangan ilmu, komponen yang digunakan bisa menggunakan berbagai macam komponen yang dianggap ada hubungannya dengan tingkat kualitas audit, selain yang telah diterapkan pada pembahasan studi ini sehingga hasil penelitiannya akan beraneka ragam.

\section{Referensi}

Andriani, N., \& Nursiam. (2018). PENGARUH FEE AUDIT , AUDIT TENURE , ROTASI AUDIT DAN REPUTASI AUDITOR TERHADAP KUALITAS AUDIT (Studi Empiris Pada Perusahaan Manufaktur yang Terdaftar di Bursa Efek Indonesia Tahun 2013-2015). Riset Akuntansi Dan Keuangan Indonesia, 3(1), 29-39.

Bagus, I., \& Astika, P. (2018). Pengaruh Kompetensi , Akuntabilitas dan Independensi pada Kualitas Audit dengan Etika Auditor Sebagai Variabel Moderasi. E-Jurnal Akuntansi Universitas Udayana, 23(1), 31-59.

Darayasa, I. M., \& Wisadha, I. G. S. (2016). ETIKA AUDITOR SEBAGAI PEMODERASI PENGARUH KOMPETENSI Fakultas Ekonomi dan Bisnis Universitas Udayana ( Unud ), Bali , Indonesia PENDAHULUAN Profesi akuntan publik merupakan profesi yang memiliki peranan penting dalam melakukan audit laporan keuangan dan m. E-Jurnal Akuntansi Universitas Udayana, 15, 142-170.

Falatah, H. F., \& Sukirno. (2018). PENGARUH KOMPETENSI , INDEPENDENSI DAN MORAL REASONING AUDITOR TERHADAP KUALITAS AUDIT ( Studi Pada Kantor Inspektorat Daerah Di Propinsi Daerah Istimewa Yogyakarta ). JURNAL NOMINAL, VII(1), 82-95.

Ghozali, I. (2008). Structural Equation Modeling Metode Alternatif dengan Partial Least 
Square (PLS). Semarang: Badan Penerbit Universitas Diponegoro.

Hanjani, A., \& Rahardja. (2014). PENGARUH ETIKA AUDITOR , PENGALAMAN AUDITOR , FEE AUDIT , DAN MOTIVASI AUDITOR TERHADAP KUALITAS AUDIT ( Studi pada Auditor KAP di Semarang ). DIPONEGORO JOURNAL OF ACCOUNTING, 3(2), 1-9.

Kusumawardani, D. (2017). PENGARUH INDEPENDENSI , AUDIT FEE , DAN OBJEKTIVITAS TERHADAP KUALITAS AUDIT. Jurnal Ilmu Dan Riset Akuntansi, 6(1), 389-402.

Lesmana, R., \& Machdar, N. M. (2015). Pengaruh Profesionalisme , Kompetensi , dan Independensi Auditor Terhadap Kualitas Audit. KALBISOCIO Jurnal Bisnis Dan Komunikasi, 2(1), 33-40.

Mariyanto, B. F., \& Praptoyo, S. (2017). Pengaruh kompetensi dan independensi terhadap kualitas audit dengan etika auditor sebagai variabel moderasi. Jurnal Ilmu Dan Riset Akuntansi, 6(2), 761-779.

Ningtyas, W. A., \& Aris, M. A. (2016). INDEPENDENSI , KOMPETENSI , PENGALAMAN KERJA, DAN DUE PROFESSIONAL CARE: PENGARUHNYA TERHADAP KUALITAS AUDIT YANG DIMODERASI DENGAN ETIKA PROFESI ( Studi Empiris pada Kantor Akuntan Publik se-Jawa Tengah dan DIY ) Pendahuluan. Riset Akuntansi Dan Keuangan Indonesia, 1(1), 75-88.

Nurjanah, I. B., \& Kartika, A. (2016). PENGARUH KOMPETENSI, INDEPENDENSI, ETIKA, PENGALAMAN AUDITOR, SKEPTISME PROFESIONAL AUDITOR, OBJEKTIFITAS DAN INTEGRITAS TERHADAP KUALITAS AUDIT. Dinamika Akuntansi, Keuangan Dan Perbankan, 5(2), 123-135.

Prabhawanti, P. P., \& Widhiyani, N. L. S. (2018). Pengaruh Besaran Fee Audit dan Independensi Terhadap Kualitas Audit dan Etika Profesi Auditor Sebagai Moderasi Fakultas Ekonomi dan Bisnis Universitas Udayana ( Unud ), Bali , Indonesia Fakultas Ekonomi dan Bisnis Universitas Udayana ( Unud ), Bali , Indo. E-Jurnal Akuntansi Universitas Udayana, 24(3), 2247-2273.

Trihapsari, D. A., \& Anisykurlillah, A. (2016). PENGARUH ETIKA,INDEPENDENSI,PENGALAMAN AUDIT DAN PREMATURE SIGN OFF TERHADAP KUALITAS AUDIT. Accounting Analysis Journal, 5(1), 1-7.

Uly, Y. A. (2019). Sosok Kasner Sirumapea, Auditor Laporan Keuangan Garuda yang Bermasalah. Economy.Okezone.Com.

Wardhatul, A., In, K., \& Asyik, N. F. (2019). Pengaruh kompetensi dan independensi terhadap kualitas audit dengan etika auditor sebagai variabel pemoderasi. Jurnal Ilmu Dan Riset Akuntansi, 8(8), 1-15.

Wiratama, W. J., \& Budiartha, K. (2015). PROFESSIONAL CARE DAN AKUNTABILITAS TERHADAP KUALITAS AUDIT. E-Jurnal Akuntansi Universitas Udayana, 10(1), 91-106. 